\title{
Work related musculo-skeletal disorders (WMDSs) of the workers engaged in tailoring units
}

\author{
MIRA KALITA, NANDITA BHATTACHARYYA AND RUPLEKHA BORAH
}

Received: 23.08.2016; Revised: 17.10.2016; Accepted: 30.10.2016

See end of the paper for authors' affiliations

\section{MIRA KALITA}

Department of Family Resource Management, College of Home Science, Assam Agricultural University, JORHAT (ASSAM) INDIA

Email : mirakalita72@yahoo.com
ABSTRACT : Work related musculo-skeletal disorders (WMSDs) are common health problem throughout the world. Assessment of exposure levels to WMSDs risk factors can be an appropriate base for planning and implementing interventional ergonomics programmes in the workplace. The presents study is focused on posture analysis of the workers working in tailoring units. For the purpose OWAS (Ovaku work posture analysis) method was used to assess specific body postures of the workers and recommend the changes to be made in the body postures while working. The prevalence of WMSDs was studied by using NMQ. The study was conducted on 100 workers engaged in various process of tailoring activities of Jorhat district of Assam, India. The photographs of different sections like measuring, marking, cutting, stitching garments and running wheel etc. showing different movements of the workers during performance of activities was observed. Postural analysis of workers found that 100 per cent workers have some harmful effect on musculo-skeletal system. Light stress, no immediate action is necessary, but changes should be considered in future working in acceptable posture and requires no corrective measures. All the respondents perceived moderate type of joint pain in the body during performances of different sub-activities. Cent per cent of the respondent experienced very severe pain in eye, neck, shoulders, legs, knees, calf muscle and feet. For increasing efficiency and reducing disorders of the workers their working posture should be changed.

KEY WORDS: Posture analysis, OWAS, Risk levels, WMSDs

- HOW TO CITE THIS PAPER : Kalita, Mira, Bhattacharyya, Nandita and Borah, Ruplekha (2016). Work related musculo-skeletal disorders (WMDSs) of the workers engaged in tailoring units. Asian J. Home Sci., 11 (2) : 378-381, DOI: 10.15740/HAS/AJHS/11.2/378-381. 